ISSN 1984-3534

\title{
ROTEIRIZAÇÃO DE VEÍCULOS: APLICAÇÃO DO PROBLEMA DO CAIXEIRO VIAJANTE EM UMA DISTRIBUIDORA DE LATICÍNIOS ${ }^{1}$
}

\author{
Rafael de Azevedo Palhares ${ }^{a}$, Rodolfo de Azevedo Palhares ${ }^{b}$ \\ Maria Creuza Borges de Araújo ${ }^{c *}$ \\ aDepartamento de Engenharia de Produção \\ Universidade Federal do Rio Grande do Norte - UFRN, Natal - RN, Brasil \\ ${ }^{\text {b}}$ Departamento de Engenharia Civil \\ Universidade Nacional de Brasília - UnB, Brasília-DF, Brasil \\ 'Departamento de Engenharia de Produção \\ Universidade Federal de Campina Grande - UFCG, Sumé-PB, Brasil
}

Recebido 21/08/2018, aceito 31/05/2019

\begin{abstract}
RESUMO
Frente ao cenário empresarial cada vez mais competitivo, é essencial o uso de planos estruturados de roteirização. Assim, o objetivo deste trabalho consiste na definição de uma nova configuração de rotas para a distribuição dos produtos de uma indústria de laticínios a partir do Problema do Caixeiro Viajante. Frente ao grande número de variáveis analisadas e a limitações nas resoluções computacionais, o método heurístico do Vizinho Mais Próximo (VMP) foi aplicado para que uma rota geral fosse devidamente definida. Feito isto, rotas diárias, visando à maximização da utilização da capacidade do veículo, foram determinadas. Em seguida, as rotas diárias foram otimizadas com a implementação do modelo matemático de Dantzig. Identificou-se uma redução de aproximadamente 3.513,2 quilômetros por mês, impactando em uma economia mensal estimada em 3.111,70 reais. Assim, o plano de rotas proposto acarretará na eficiência logística, bem como na minimização dos custos de transporte da empresa.
\end{abstract}

Palavras-chave: Roteirização, Problema do caixeiro viajante, Otimização, Laticínios.

\begin{abstract}
In the increasingly competitive business environment, the employability of structured routing plans is essential. Thus, the purpose of this paper is to define a new route configuration for the distribution of the products of a dairy industry from the Traveling Salesman Problem. Given a large number of variables analyzed and limitations in computational resolutions, the heuristic method of the Nearer Neighbor was applied so that a general route was defined correctly. Following, daily itineraries, aiming at maximizing the utilization of vehicle capacity were determined. Then, the regular routes were optimized with the implementation of the Dantzig mathematical model. A reduction of approximately 3,513.2 kilometers per month was identified, impacting on a monthly economy estimated at $3,111.70$ reais. Thus, the proposed route plan will entail logistics efficiency as well as minimization of company costs.
\end{abstract}

Keywords: Routing, Traveling salesman problem, Optimization, Dairy products.

*Autor para correspondência. E-mail: mariacreuzaborges@ yahoo.com.br.

DOI: 10.4322/PODes.2019.008 


\section{Introdução}

Diante do cenário competitivo cada vez mais acirrado no qual as organizações estão inseridas, a eficiência logística tem se tornado uma fonte essencial de vantagem competitiva. Assim, as empresas buscam fornecer seus produtos conforme as especificações exigidas, visando à minimização dos custos. Segundo Peres (2011), a logística é crucial para diversos setores industriais, inclusive a indústria de laticínios. Ainda de acordo com o autor, as evoluções tecnológicas referentes à mesma tornam a logística substancial para as organizações. Neste sentido, estudos referentes aos problemas de roteirização de veículos (PRV) têm sido cada vez mais considerados por autores de diversas áreas, principalmente pelos profissionais das áreas de logística e pesquisa operacional (Salas et al., 2010).

De acordo com Caria et al. (2018), a partir de um plano estruturado de roteirização, os veículos podem ser otimizados, as rotas podem ser devidamente planejadas e a eficiência operacional atendida através da redução de quilometragem, custos com combustível, manutenção geral dos veículos, bem como o aperfeiçoamento das informações gerenciais. Estes resultados impactam proporcionalmente na redução dos custos logísticos e no aumento da qualidade na prestação do serviço ofertado, e revelam que a elaboração empírica de planos de rotas pode acarretar custos desnecessários, bem como na ineficiência logística.

Leite e Júnior (2017) ressaltam a importância da roteirização para as organizações, já que benefícios significativos, tanto referentes aos custos operacionais quanto acerca da qualidade na prestação serviço, são potencializados a partir da mesma. Estes benefícios agregam valor à empresa no tocante ao seu posicionamento competitivo perante o mercado. Ademais, Ribeiro et al. (2018) abordam que os produtos perecíveis são suscetíveis a irregularidades em sua qualidade caso não sejam adequadamente embalados, transportados, conservados e consumidos no prazo de validade estimado. Para o autor, estas características tornam o estudo de transporte de cargas perecíveis ainda mais crítico. Desta forma, faz-se necessário uma logística de transporte eficiente, uma vez que tais produtos comumente demandam curto prazo de consumo.

Neste contexto, o presente trabalho visa realizar o estudo de roteirização da distribuição de produtos em uma empresa do setor de laticínios situada em Angicos/RN com a aplicação do Problema do Caixeiro Viajante. Devido à complexidade dos problemas de roteirização, classificados como NP-Hard, utilizou-se a Heurística do Vizinho Mais Próximo (VMP) para a determinação das rotas diárias, considerando a capacidade máxima do veículo, já que esta heurística possui um algoritmo simples, capaz de fornecer resultados adequados, e com rapidez, para problemas com um número elevados de pontos a considerar. Em seguida, cada rota foi otimizada pelo Modelo de Dantzig, a fim de melhorar os resultados obtidos para cada um dos clusters.

Este artigo está organizado como segue: na Seção 2, é apresentado o referencial teórico da pesquisa. Estudos recentes realizados na área de roteirização de veículos são apresentados na Seção 3. Em seguida, a metodologia e o estudo de caso são classificados nas Seções 4 e 5, respectivamente. Na Seção 6, os resultados são discutidos e, por fim, as conclusões são abordadas na Seção 7.

\section{Roteirização de Veículos}

Para Silva e Sanches (2009), a roteirização de veículos consiste em problemas de transporte que tem o intuito de identificar as melhores rotas a serem realizadas, a fim de atender um conjunto de pontos exibidos a partir de um grafo, no qual as arestas configuram as rotas e os vértices os clientes a serem visitados. Neste sentido, o objetivo é determinar as rotas que atendam a todos os pontos a serem visitados percorrendo a menor distância (Franco Júnior e Oliveira, 2012). Estes problemas são classificados como NP-Difícil (Tempo polinomial não determinístico - Difícil) que compreendem, de modo geral, problemas nos quais aumentos mínimos no escopo acarretam em impactos significativos no esforço e tempo computacional correspondentes a identificação de uma solução ótima (Bang-Jensen e Hell, 1990). 
Desta forma, para Laporte (1992), os Problemas de Roteirização de Veículos (PRV) são resolvidos através de algoritmos exatos, que resultam na solução ótima do problema, ou métodos heurísticos, que não necessariamente garantem a solução ótima, porém, identificam soluções viáveis. Souza et al. (2016) ressaltam que na literatura existem vários métodos voltados à solução de problemas de roteirização. Estes métodos objetivam a identificação do trajeto no qual os custos de transporte sejam reduzidos ou minimizados, de modo que a demanda seja atendida e as restrições de capacidade dos veículos sejam respeitadas (Tormen et al., 2018).

\subsection{Problema do Caixeiro Viajante}

Para Ahmed et al. (2017), o Problema do Caixeiro Viajante (PCV) pode ser classificado como um problema de roteirização, no qual pretende-se definir uma única rota que passe em cada nó de um grafo, apenas uma única vez, retornando ao nó inicial ao fim do percurso. Ainda para o autor, uma das primeiras situações envolvendo problemas de roteirização de veículos abordados na literatura foi o PCV. Matai et al. (2010) afirmam que para aplicação desse método deve-se tomar conhecimento das cidades e distâncias ou o custo que represente o trajeto entre estas, de modo a identificar uma rota otimizada, ou seja, aquela que minimize a distância total percorrida. A partir do ponto de origem, todos os pontos demandados devem ser atendidos, porém, somente visitados uma única vez. Feito isso, o veículo retorna ao ponto de origem. O resultado baseia-se na ordem sequencial dos pontos a serem visitados. Logo, a aplicação deste método é adequada ao presente estudo, cuja situação ajusta-se as restrições do PCV (Ahmed et al., 2017).

Goldbarg e Luna (2005) expõem o modelo matemático do Problema do Caixeiro Viajante. Esta formulação de Dantzig apresenta a restrição binária exibida a seguir.

$$
\operatorname{Minimizar} Z=\sum_{j=1}^{n} C_{i j} X_{i j}
$$

\section{Sujeito a}

$$
\begin{aligned}
& \sum_{j=1}^{n} X_{i j}=1 \quad \forall_{i} \in N \\
& \sum_{i=1}^{n} X_{i j}=1 \quad \forall_{i} \in N \\
& \sum_{i=1}^{n} X_{i j} \leq|S|-1 \quad \forall_{S} \subset N \\
& x_{i j} \in 0,1 \forall_{i} \in N
\end{aligned}
$$

Onde:

(1) Função objetivo;

(2) Restrição que determina que o caixeiro entre em cada cidade uma única vez;

(3) Restrição que determina que o caixeiro saia de cada cidade uma única vez;

(4) Esta restrição exclui subciclos (ciclos hamiltonianos) das alternativas. $|S|$ é o número de vértices do grafo $S$;

(5) Restrição binária, atribui-se o valor 1 se o percurso de uma cidade para outra é utilizado. Caso contrário, a variável receberá o valor 0 .

O PCV fundamenta-se no cálculo de todas as possibilidades de rotas até que a solução com menor custo (distância) total dentre todas as possibilidades seja atingida. Logo, esta abordagem é 
classificada como brute force method ou pesquisa exaustiva, uma vez que em uma análise de $n$ pontos a serem atendidos existem (n-1)! soluções possíveis, de forma que em casos na qual vários destinos sejam considerados, o algoritmo exato passe a não ser exequível em tempo hábil (Martins e Lopes, 2014).

Nestes casos, deve-se utilizar métodos heurísticos, que são aplicados para a obtenção de soluções viáveis do problema em um tempo computacional factível. Estes não necessariamente resultam em uma solução ótima, porém, satisfatória ao problema. Suas aplicações fundamentamse em um tratamento intuitivo dos dados, de modo que as particularidades do problema possam ser analisadas de modo racional e inteligente (Johnson, 1974).

Um dos métodos heurísticos adotados para a resolução do problema do caixeiro viajante é o método do Vizinho Mais Próximo (VMP). A heurística VMP consiste na escolha da cidade mais próxima a cada deslocamento, desde que todas as cidades sejam unicamente visitadas e o caixeiro retorne ao ponto de origem. Os passos para sua solução são: inicie o algoritmo pela cidade i $(\mathrm{i}=1,2, \ldots, \mathrm{n})$ e, em seguida, ligue a cidade $\mathrm{i}$ com a cidade $\mathrm{j}(\mathrm{j}=1,2, \ldots, \mathrm{n})$ mais próxima de $\mathrm{i}$, repita $\mathrm{o}$ procedimento até que o circuito com as n cidades seja concluído. Vale salientar que cada ponto só pode ser visitado uma única vez (Teixeira, 2014). O clássico algoritmo para a solução desta heurística foi descrito pioneiramente por Bellmore e Nemhauser (1968) como segue.

1. Escolha vértice inicial $\mathrm{v} \in \mathrm{V}$. Faça $\mathrm{C} \leftarrow$ (v)

2. Repita $\mathrm{n}-1$ vezes

3. Seja $\mathrm{C}=\left(\mathrm{v}_{1}, \ldots, \mathrm{v}_{\mathrm{i}}\right)$

4. Escolha um vértice u mais próximo de um dos extremos de $C$

5. Acrescente u na respectiva extremidade

6. Devolva C

De acordo com Calado e Ladeira (2011), a recomendação da utilização do método VMP é dada por sua fácil aplicação para obtenção de uma solução viável, mesmo que não ótima.

\section{Estudos sobre Roteirização de Veículos}

Devido à importância da roteirização para as organizações, vários autores realizaram pesquisas relacionadas a esse tema e diversas metodologias são difundidas na literatura.

Neste contexto, o estudo de caso abordado na pesquisa de Song e Ko (2016) abrangem o problema de roteirização para veículos refrigerados, designados à distribuição de produtos alimentares perecíveis. Considerou-se as seguintes restrições do problema: quantidade de produtos transportados para cada cliente; tempo de entrega; quantidade de veículos disponíveis refrigerados e não refrigerados. Em seguida, os autores desenvolveram um modelo matemático não-linear e um algoritmo heurístico para a geração de rotas eficientes.

Layeb et al. (2013) apresentam um algoritmo GRASP baseado em uma heurística randomizada e um procedimento de Simulated Annealing como fase de melhoria para resolver o problema de roteamento de veículos capacitados. O método requer quatro etapas para gerar soluções iniciais viáveis, e posteriormente o recozimento simulado aprimora essas soluções encontradas para alcançar a solução ideal. Ancau (2005) apresentou um método heurístico para a resolução de pequenas e médias distâncias dos PCV simétricos, ou seja, problemas em que as distâncias de i para j é exatamente igual à distância de j para i. Este método levanta as coordenadas $(\mathrm{X}, \mathrm{Y})$ das cidades estudadas e baseia-se em duas principais etapas de resolução. Na primeira etapa é elaborada uma permutação aleatória das cidades a serem visitadas. Desta forma, a partir da primeira ordem aleatória gerada, uma rota constituída por uma técnica de inserção, que tem como critério de seleção o custo do comprimento entre as cidades, é aplicada. Em seguida, é utilizada uma técnica para remover os segmentos transversais na rota, de forma que a mesma possa ser melhorada.

A pesquisa de Cacchiani et al. (2014) referem-se à resolução de um Problema de Roteirização Periódica de Veículos a partir de um algoritmo de otimização híbrida para programação linear mista inteira, introduzindo componentes heurísticos e exatos. Desta forma, o algoritmo consiste em identificar um conjunto de rotas para cada dia de um horizonte de tempo, no qual o custo total de cada rota seja minimizado. Ewbank et al. (2016) apresentaram a proposta 
de uma técnica heurística que identifica melhores resultados de agrupamentos aplicados ao PRV, de forma que o tempo computacional fosse reduzido. Esta heurística visa aglomerar pontos a serem atendidos em clusters de modo que a distância mínima do percurso e restrição de capacidade do veículo seja considerada em cada cluster. Desta forma, este método determina melhores rotas dentro de cada cluster.

Seixas (2013) trata de um problema de roteirização de veículos com restrições de acessibilidade dos pontos a serem visitadas, janelas de tempo, deslocamento considerando velocidade medida, frota heterogênea em relação à capacidade de carga e custo. Neste problema estudado, o veículo inicia e terminas o percurso de diversas rotas diariamente. Vale ressaltar que o total de horas trabalhadas é considerado e que apenas um motorista é designado para esta função. É proposto pelo autor um algoritmo fundamentado em geração de colunas, agregado a um procedimento de branch-and-bound.

Souza Neto (2016) propõe um modelo de programação linear misto que agrega os custos oriundos da frota própria e também os veículos fretados em uma empresa distribuidora de bebidas. Neste modelo as restrições de janelas de tempo, múltiplas rotas diárias, capacidade transportada, restrição de tempo de circulação do veículo em locais específicos, tempo máximo a ser executado bem como o carregamento mínimo para que uma segunda viagem seja iniciada.

O problema de roteirização estudado nesta pesquisa adequa-se às restrições do Problema do Caixeiro Viajante. A abordagem de Ewbank et al. (2016), Layeb et al. (2013) e Ancau (2005) bem como outros métodos heurísticos, tais como o Método de Varredura e K-OPT, adéquam-se ao problema aqui estudado, porém, possuem maior complexidade em relação ao VMP e podem requer a utilização de softwares específicos para obtenção de rotas viáveis.

O modelo não linear apresentado por Song e Ko (2016), e o modelo linear misto de Souza Neto (2016) abordam uma metodologia mais complexa e considera restrições que não se adequam ao problema em questão, tais como: tempo de entrega e disponibilidade de mais de um tipo de veículo, restrições de janelas de tempo, restrição de tempo de circulação do veículo em locais específicos e tempo de carregamento. O algoritmo de otimização híbrida de Cacchiani et al. (2014) também não se adequa ao problema em questão, pois considera situações nas quais mais de um veículo está disponível. Da mesma forma, o problema estudado por Seixas (2013) também não se adequa, uma vez que são consideradas restrições de janelas de tempo, total de horas trabalhadas e a frota é heterogênea.

Assim, para que os clusters formados dispusessem de pontos mais próximos entre si e, posteriormente, fossem transformados em rotas diárias, aplicou-se a heurística do VMP. Este método heurístico dispõe de uma metodologia simples e exequível, sem a utilização de softwares específicos, por isto foi adotado nesta pesquisa. Em seguida, para minimizar a distância total de cada uma das rotas diárias, o modelo matemático de Dantzig que compreende ao PCV foi inserido na ferramenta Microsoft Excel @Solver, de modo que estas fossem otimizadas.

\section{Metodologia}

De acordo com Gerhardt e Silveira (2009), a presente pesquisa é classificada, quanto à sua natureza, como aplicada, já que se propôs a elaborar um novo o plano de rotas referente à distribuição de produtos laticínios da empresa A, situada em Angicos/RN. Quanto ao caráter, é classificada como exploratório, que, segundo Gil (2007), visa expandir o conhecimento do autor sobre o problema estudado. Segundo Chung (2004), o método de pesquisa é classificado como modelagem e simulação, uma vez que o processo de distribuição é representado a partir de um modelo matemático computadorizado. Corroborando com isto, Pereira (2000) afirma que a simulação computacional é a configuração de um sistema existente a partir de um modelo elaborado em um computador. A abordagem é de cunho quantitativo, para isto, modelos matemáticos são implementados para obtenção das causas do fenômeno estudado e as relações entre variáveis (Fonseca, 2002). A Figura 1 expõe as etapas da pesquisa. 
Figura 1: Etapas da pesquisa.

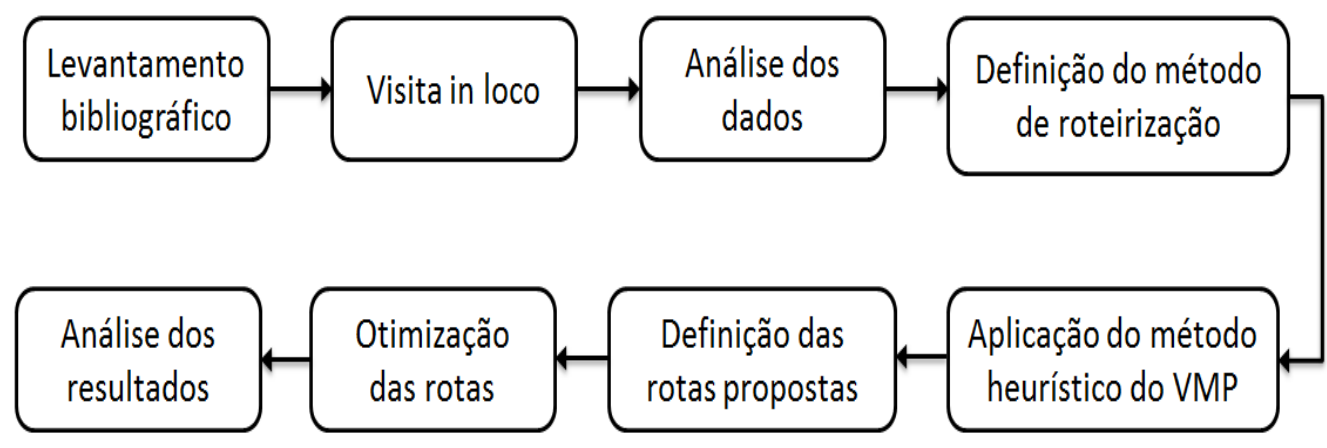

Fonte: Elaborada pelos autores.

Inicialmente, realizou-se um levantamento bibliográfico para melhor embasamento teórico sobre logística de distribuição, o papel do transporte na logística, bem como no conhecimento referente aos métodos de roteirizarão de veículos mais estudados na literatura. A coleta de dados foi realizada a partir de visitas in loco por meio de entrevistas não estruturadas aos gestores e motoristas, acesso a documentos e registros das rotas existentes de modo que os pontos de entrega atendidos semanalmente, tipos de produtos distribuídos, tipo do veículo designado, capacidade do veículo, bem como as restrições do problema. Feito isto, o plano de rotas atual pôde ser identificado.

Neste contexto, observou-se que um único veículo é designado a todas as rotas diárias e que cada ponto só pode ser atendido uma única vez por dia. Em seguida, o veículo deve regressar ao ponto de origem em cada dia. Desta forma, o problema adéqua-se às restrições do Problema do Caixeiro Viajante (PCV). A partir da análise dos dados obtidos e com o auxílio da ferramenta Google Maps, foi possível elaborar a matriz relação de distâncias entre todos os pontos a serem visitados semanalmente. Em seguida, procurou-se identificar os pontos mais próximos entre si com a aplicação do método heurístico do Vizinho Mais Próximo (VMP). Tendo as rotas diárias devidamente definidas, estas foram otimizadas a partir da inserção do modelo matemático de Dantzig. Por fim, os resultados foram analisados para que os impactos provenientes da implantação do plano de rotas propostos fossem observados e apresentados em uma análise comparativa com o plano atualmente executado pela empresa.

\section{Estudo de Caso}

A empresa analisada situa-se na cidade de Angicos, no Estado do Rio Grande do Norte. Os produtos distribuídos são classificados em 3 tipos: leite comercial; leite institucional e bebidas lácteas fermentadas. A sua demanda média semanal é de aproximadamente 23.955 litros de leite institucional, 30.100 litros de leite comercial e 4.600 litros de bebidas lácteas.

Apesar do pequeno porte, a empresa estudada é extremamente importante para o cenário econômico da região. Ela fomenta as atividades de ovinocaprinocultura, subsidia produtores rurais locais assistindo mais de 31 produtores da região, gerando empregos diretos e indiretos bem como fornece seus produtos para atender a demanda de toda região em que esta inserida.

\subsection{Plano Atual de Rotas de Angicos com Sentido a Natal}

As rotas de distribuição realizadas pela empresa foram constituídas de forma empírica, isto é, baseadas em experiências e vivências dos próprios gestores e motoristas, de forma que nenhuma técnica estruturada de roteirização havia sido aplicada no planejamento dos itinerários da empresa. Esta elaboração de rotas pode acarretar custos desnecessários, bem como a ineficiência logística, uma vez que as rotas não são devidamente planejadas. Estes resultados impactam 
proporcionalmente no aumento dos custos de transporte, manutenção geral dos veículos, insuficiência das informações gerenciais e qualidade na prestação do serviço ofertado.

As rotas atuais são realizadas semanalmente, nos seguintes dias: segunda-feira; terça-feira; quarta-feira; quinta-feira; sexta-feira e sábado. Vale salientar que dois pontos de entrega são visitados todos os dias, o primeiro ponto é na Rua Macaé e o segundo é o ponto situado na Rua Érico Veríssimo, ambos em Natal. Estes dois pontos são centros de distribuição que recebem os produtos comerciais e se encarregam de distribuí-los ao varejo. Os demais pontos correspondem à distribuição do leite institucional, em instituições públicas, tais como escolas e hospitais. Na segunda-feira, 12 pontos são visitados. Este itinerário é mostrado no Quadro 1.

Quadro 1: Plano de rota atual: Segunda-feira.

\begin{tabular}{|c|l|}
\hline $\begin{array}{c}\text { Ordem de } \\
\text { visitas }\end{array}$ & \multicolumn{1}{c|}{ Pontos a serem atendidos } \\
\hline 1 & Angicos/RN \\
\hline 2 & Caiçara do Rio do Vento/RN \\
\hline 3 & Riachuelo/RN \\
\hline 4 & Rui Barbosa/RN \\
\hline 5 & Lagoa de Velhos/RN \\
\hline 6 & Bento Fernandes/RN \\
\hline 7 & Natal/RN (Zona Norte, Rua Macaé) \\
\hline 8 & Natal/RN (Rua Érico Veríssimo, Candelária) \\
\hline 9 & Natal/RN (Rua Teotônio Freire, Ribeira) \\
\hline 10 & Nata/RN (Rua Coronel Joaquim Manoel, Petrópolis) \\
\hline 11 & Santa Maria/RN \\
\hline 12 & Angicos/RN \\
\hline & Fonte: Elaborado pelos autores. \\
\hline
\end{tabular}

A quantidade total de produtos transportados nesta rota é de aproximadamente 15.000 litros, na qual 8.600 litros correspondem ao leite institucional, 5.300 litros ao leite comercial e 1.100 litros são equivalentes às bebidas lácteas fermentadas, como exposto no Quadro 2.

Quadro 2: Plano de rota atual: Terça-feira.

\begin{tabular}{|c|l|}
\hline $\begin{array}{c}\text { Ordem de } \\
\text { visitas }\end{array}$ & \multicolumn{1}{c|}{ Pontos a serem atendidos } \\
\hline 1 & Angicos/RN \\
\hline 2 & São Paulo do Potengi/RN \\
\hline 3 & Natal/RN (Zona Norte, Rua Macaé, Potengi) \\
\hline 4 & Natal/RN (Rua Érico Veríssimo, Candelária) \\
\hline 5 & Natal/RN (Rua João XXIII, Mãe Luíza) \\
\hline 6 & Natal/RN (Rua Dr. Mario Negócio, Quintas) \\
\hline 7 & Angicos/RN \\
\hline & Fonte: Elaborado pelos autores. \\
\hline
\end{tabular}

A programação de distribuição para este dia corresponde a 4.625 litros do leite institucional, aproximadamente 4.500 litros do leite comercial e 800 litros de bebidas lácteas. Neste contexto, identifica-se que o total de produtos transportados na terça-feira é de aproximadamente 9.925 litros.

$\mathrm{Na}$ quarta-feira, apenas os pontos de distribuição dos produtos comerciais são visitados. Assim, são distribuídos aproximadamente 4.600 litros de leite comercial e 800 litros de bebidas 
lácteas, resultando em um total de 5.400 litros de produtos transportados. Na quinta-feira, 6 pontos devem ser visitados conforme exibido no Quadro 3. A quantidade total de produtos transportados nesta rota é de aproximadamente 9.410 litros, na qual 4.810 litros correspondem ao leite institucional, 4.100 litros ao leite comercial e 500 litros são equivalentes às bebidas lácteas fermentadas.

Quadro 3: Plano de rota atual: Quinta-feira.

\begin{tabular}{|c|l|}
\hline $\begin{array}{c}\text { Ordem de } \\
\text { visitas }\end{array}$ & \multicolumn{1}{c|}{ Pontos a serem atendidos } \\
\hline 1 & Angicos/RN \\
\hline 2 & Pedra Preta/RN \\
\hline 3 & Lajes/RN \\
\hline 4 & São Paulo do Potengi/RN \\
\hline 5 & Natal/RN (Zona Norte, Rua Macaé) \\
\hline 6 & Natal/RN (Rua Érico Veríssimo, Candelária) \\
\hline 7 & Natal/RN (Rua Ferreira Nobre, Alecrim) \\
\hline 8 & Angicos/RN \\
\hline & Fonte: Elaborado pelos autores. \\
\hline
\end{tabular}

Na sexta-feira rota, 6 pontos de distribuição são atendidos e todos estes concentram-se na cidade de Natal/RN, conforme exibido no Quadro 4. Aproximadamente 5.250 litros do leite institucional, 6.200 litros do leite comercial e 900 das bebidas lácteas são distribuídos nesta rota, o que resulta em um total de 12.350 litros de produtos transportados.

Quadro 4: Plano de rota atual: Sexta-feira.

\begin{tabular}{|c|l|}
\hline $\begin{array}{c}\text { Ordem de } \\
\text { visitas }\end{array}$ & \multicolumn{1}{c|}{ Pontos a serem atendidos } \\
\hline 1 & Angicos/RN \\
\hline 2 & Natal/RN (Zona Norte, Rua Macaé) \\
\hline 3 & Natal/RN (Rua Érico Veríssimo, Candelária) \\
\hline 4 & Natal/RN (Rua Dinarte Mariz Neto, Nova Descoberta) \\
\hline 5 & Natal/RN (Av. Coronel Estevam, Alecrim) \\
\hline 6 & Natal/RN (Bairro Passo da Pátria) \\
\hline 7 & Natal/RN (E. E. José Frazão) \\
\hline 8 & Angicos/RN \\
\hline & Fonte: Elaborado pelos autores. \\
\hline
\end{tabular}

O sequenciamento de pontos a serem visitados no sábado é mostrado no Quadro 5. A quantidade total de produtos transportados neste dia equivale a aproximadamente 6.900 litros. Deste total, 1.000 litros correspondem ao leite institucional, 5.400 litros ao leite comercial e 500 litros as bebidas lácteas fermentadas. A Tabela 2 apresenta o plano de rotas atual, considerando as distâncias estimadas e totais demandado em cada dia.

Como é possível identificar na Tabela 1, a baixa utilização da capacidade do veículo, principalmente na Terça feira, Quarta-Feira, Quinta-feira e Sábado nos mostra que a utilização deste recurso não está sendo realizada de forma adequada. Assim, um plano estruturado de roteirização faz-se necessário para que a utilização deste recurso seja aproveitada de forma eficiente. 
Quadro 5: Plano de rota atual: Sábado.

\begin{tabular}{|c|l|}
\hline $\begin{array}{c}\text { Ordem de } \\
\text { visitas }\end{array}$ & \multicolumn{1}{c|}{ Pontos a serem atendidos } \\
\hline 1 & Angicos/RN \\
\hline 2 & Natal/RN (Zona Norte, Rua Macaé) \\
\hline 3 & Natal/RN (Rua Érico Veríssimo, Candelária) \\
\hline 4 & Natal/RN (Av. Solange Nunes do Nascimento, Cidade Nova) \\
\hline 5 & Angicos/RN \\
\hline
\end{tabular}

Fonte: Elaborado pelos autores.

Tabela 1: Volume de distribuição e total de quilômetros percorridos.

\begin{tabular}{|c|c|c|c|}
\hline $\begin{array}{c}\text { Dias na } \\
\text { semana }\end{array}$ & $\begin{array}{c}\text { Demanda total } \\
\text { (litros) }\end{array}$ & $\begin{array}{c}\text { Total percorrido } \\
(\mathbf{K m})\end{array}$ & $\begin{array}{c}\text { Utilização da capacidade } \\
(\mathbf{\%})\end{array}$ \\
\hline Segunda-feira & 15.000 & 561 & 100,00 \\
\hline Terça-feira & 9.925 & 399 & 66,17 \\
\hline Quarta-feira & 5.400 & 360 & 36,00 \\
\hline Quinta-feira & 9.410 & 483 & 62,73 \\
\hline Sexta-feira & 12.350 & 384 & 82,33 \\
\hline Sábado & 6.900 & 362 & 46,00 \\
\hline
\end{tabular}

Fonte: Elaborada pelos autores.

\subsection{Estruturação do Novo Plano de Rotas}

Destaca-se que 22 pontos são visitados para atender a toda a demanda semanal da empresa. Estes pontos são representados pelos seguintes códigos: $\mathbf{A}=$ Angicos; $\mathbf{B}=$ São Paulo do Potengi/; $\mathbf{C}=$ Pedra Preta/; D=Lajes/RN; $\mathbf{E}=$ Caiçara do Rio do Vento; $\mathbf{F}=$ Riachuelo; $\mathbf{I}=$ Ruy Barbosa; $\mathbf{J}=$ Lagoa de Velhos; K= Bento Fernandes; $\mathbf{L}=$ Santa Maria; $\mathbf{M}=$ Rua Macaé, Natal/; $\mathbf{N}=$ Rua Érico Veríssimo, Candelária, Natal/; $\mathbf{O}=$ Rua Teotônio Freire, Ribeira, Natal; $\mathbf{P}=$ Rua Coronel Joaquim Manoel, Petrópolis, Natal; Q= Rua João XXIII, Mãe Luíza, Natal; $\mathbf{R}=$ Rua. Dr. Mario Negócio, Quintas, Natal; $\mathbf{S}=$ Rua Ferreira Nobre, Alecrim, Natal; $\mathbf{T}=$ Rua Dinarte Mariz Neto, Nova Descoberta, Natal; $\mathbf{U}=$ Av. Coronel Estevam, Alecrim, Natal; V= Av. Capitão-Mor Gouveia, Felipe Camarão, Natal/RN; W= Av. Boa Sorte, Nossa Sra. da Apresentação, Natal; Y=Av. Solange Nunes do Nascimento, Cidade Nova, Natal. Além disso, o problema possui algumas características importantes, expostas no Quadro 6.

Quadro 6: Características do problema.

\begin{tabular}{|l|c|}
\hline \multicolumn{2}{|c|}{ Características } \\
\hline Frota & Homogênea \\
\hline Capacidade do veículo & 15.000 litros \\
\hline Depósito & Ponto de partida e chegada \\
\hline
\end{tabular}

Fonte: Elaborado pelos autores. 
Faz-se necessário ainda a definição da função objetivo, restrições relacionadas aos clientes e aos veículos, as variáveis de decisão e as características do problema, em que:

1. Função objetivo: Minimizar as distâncias percorridas para redução dos custos de transporte.

2. Restrições:

i. apenas um veículo com capacidade de $15.000 \mathrm{~L}$;

ii. a cidade de São Paulo do Potengi/RN é o único ponto visitado duas vezes na semana, com intervalo mínimo de um dia;

iii. nesta mesma cidade, a demanda semanal deve ser dividida em 50\% para cada um dos dois dias de visita.

3. Variáveis de decisão: A decisão atual é escolher a melhor rota para o veículo.

Como os problemas de roteirização são classificados como NP - Difícil e a restrição de capacidade do veículo deve ser atendida, clusters puderam ser formados a partir da aplicação da heurística do VMP, de modo que cada cluster representasse uma rota na qual a utilização da capacidade do veículo pudesse ser eficientemente utilizada. Destaca-se que se optou por esta heurística pela sua fácil aplicação e fornecimento de um resultado viável para um conjunto de 22 pontos. Assim, tendo que A é o ponto de origem, ou seja, a indústria de laticínios, o procedimento da aplicação da heurística do VMP será iniciado no mesmo.

A Figura 2 expõe um grafo do roteiro geral após a aplicação do método do VMP. Ressaltase que os valores apresentados na imagem próximos às setas que interligam os pontos, representam a distância estimada em quilômetros entre eles. Os valores abaixo representam a demanda em litros em cada ponto.

A partir desta análise, cada cluster foi considerado uma rota viável a ser designada aos dias da semana, de modo que a demanda e a capacidade do veículo seja considerada. Assim, tendo a capacidade do veículo utilizada de forma eficiente e atendendo a exigência do cliente da cidade São Paulo do Potengi/RN, faz-se necessário otimizar cada uma destas rotas, de modo que a distância estimada percorrida seja a menor possível.

A Rota 1 é formada por um cluster que agrupa 11 pontos de destino (A;D;E;F;L;B;J;I;K;Y;N) e fará o aproveitamento máximo da utilização da capacidade do veículo, conforme é identificado na Tabela 2. Observa-se que no destino Rua Érico Veríssimo, não foi possível atender a toda demanda semanal em virtude da restrição de capacidade. Logo, este ponto deverá ser contemplado nas rotas subsequentes, até que sua demanda seja integralmente atendida. A Rota 2 atende a uma restrição do nosso problema na qual a cidade São Paulo do Potengi (B) deverá ser atendida em dois dias diferentes na semana e a sua demanda semanal deve ser dividida igualmente entre estes. É também contemplado nesta rota o destino Rua Érico Veríssimo, Candelária, Natal $(\mathrm{N})$ conforme apresentado na Tabela 3. Destaca-se que, devido à restrição de capacidade, a demanda semanal do ponto $\mathrm{N}$ ainda não é totalmente atendida nas Rotas 1 e 2 . Para isto, a Rota 3 deverá incorporá-la também. Desta forma, 11 pontos (A;N;V;T;U;S;R;O;P;Q;M) são agrupados na Rota 3, de modo que a utilização da capacidade seja de $100 \%$, conforme é exibido na Tabela 4. 
Figura 2: Roteiro geral após a aplicação da heurística.

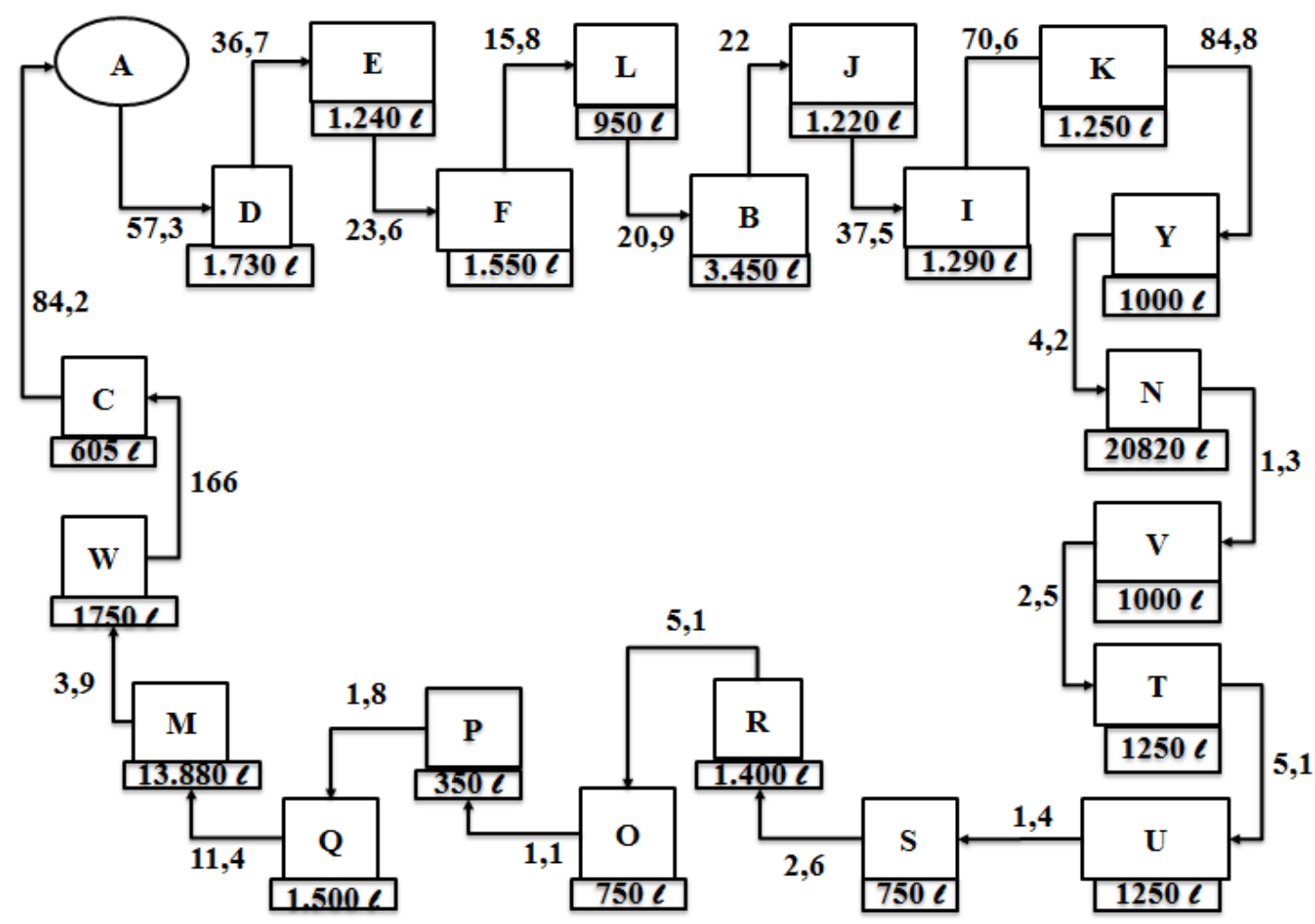

Fonte: Elaborada pelos autores.

Tabela 2: Definição da Rota 1.

\begin{tabular}{|c|c|c|}
\hline Destino & Demanda (litros) & Total transportado \\
\hline Angicos (A) & - & \multirow{12}{*}{15.000} \\
\hline Lajes (D) & 1.730 & \\
\hline Caiçara do Rio do Vento (E) & 1.240 & \\
\hline Riachuelo $(\mathbf{F})$ & 1.550 & \\
\hline Santa Maria (L) & 950 & \\
\hline São Paulo do Potengi $(\mathbf{B})$ & 1.725 & \\
\hline Lagoa de Velhos (J) & 1.220 & \\
\hline Ruy Barbosa (I) & 1.290 & \\
\hline Bento Fernandes $(\mathbf{K})$ & 1.250 & \\
\hline Av. Solange Nunes do Nascimento, Natal (Y) & 1000 & \\
\hline Rua Érico Veríssimo, Candelária, Natal (N) & 3.045 & \\
\hline Angicos (A) & - & \\
\hline
\end{tabular}

Fonte: Elaborada pelos autores.

Tabela 3: Definição da Rota 2.

\begin{tabular}{|l|c|c|}
\hline \multicolumn{1}{|c|}{ Rota 2 } & Demanda (litros) & Total transportado \\
\hline Angicos (A) & - & \multirow{2}{*}{15.000} \\
\cline { 1 - 2 } São Paulo do Potengi (B) & 1.725 & \\
\hline Rua Érico Veríssimo, Candelária, Natal (N) & 13.275 & \\
\hline Angicos (A) & - & \\
\hline
\end{tabular}

Fonte: Elaborada pelos autores. 
Tabela 4: Definição da Rota 3.

\begin{tabular}{|c|c|c|}
\hline Rota 3 & Demanda (litros) & Total transportado \\
\hline Angicos (A) & - & \multirow{12}{*}{15.000} \\
\hline Rua Érico Veríssimo, Candelária, Natal (N) & 4.500 & \\
\hline Av. Capitão-Mor Gouveia, Natal (V) & 1000 & \\
\hline Rua Dinarte Mariz Neto, Natal (T) & 1250 & \\
\hline Av. Coronel Estevam, Alecrim, Natal (U) & 1250 & \\
\hline Rua Ferreira Nobre, Alecrim, Natal (S) & 750 & \\
\hline Rua. Dr. Mario Negócio, Quintas, Natal (R) & 1.400 & \\
\hline Rua Teotônio Freire, Ribeira, Natal (O) & 750 & \\
\hline Rua Coronel Joaquim Manoel, Natal (P) & 350 & \\
\hline Rua João XXIII, Mãe Luíza, Natal (Q) & 1.500 & \\
\hline Rua Macaé, Potengi, Natal (M) & 2.250 & \\
\hline Angicos (A) & - & \\
\hline
\end{tabular}

Fonte: Elaborada pelos autores.

A Rota 4, exibida na Tabela 5, contempla apenas 3 pontos a serem visitados, dentre eles o ponto Rua Macaé, Potengi, Natal (M), pois, devido à capacidade máxima na Rota 3 ter sido atingida sem que sua demanda fosse completamente atendida, este ponto é novamente atribuído a Rota 4. Destaca-se que nesta rota a utilização máxima da capacidade não foi necessária, uma vez que toda a demanda semanal pôde ser atendida. Logo, para a mesma tem-se uma utilização de $93,24 \%$ da capacidade máxima do veículo.

Tabela 5: Definição da Rota 4.

\begin{tabular}{|l|c|c|}
\hline \multicolumn{1}{|c|}{ Rota 4 } & Demanda (litros) & Total transportado \\
\hline Angicos (A) & - & \\
\cline { 1 - 2 } Rua Macaé, Potengi, Natal (M) & 11.630 & \multirow{2}{*}{13.985} \\
\cline { 1 - 2 } Av. Boa Sorte, Natal (W) & 1.750 & \\
\cline { 1 - 2 } Pedra Preta (C) & 605 & \\
\hline Angicos (A) & - & \\
\hline
\end{tabular}

Fonte: Elaborada pelos autores.

Tendo a definição de todas as rotas semanais, a partir da heurística do Vizinho Mais Próximo, fez-se necessário à otimização de cada uma delas.

Dentre os softwares existentes, o Solver do Excel foi adotado para resolução do PCV em relação à otimização das quatro rotas de distribuição definidas. Tendo em vista que muitas variáveis deverão ser analisadas, esta ferramenta dispõe de uma abordagem prática para resolução de problemas desta natureza.

\subsubsection{Otimização das Rotas}

Para a construção da matriz relação de distância, os pontos analisados na Rota 1 foram identificados da seguinte forma: A1= Angicos; B1=Lajes; C1=Caiçara do Rio do Vento; D1=Riachuelo; E1=Santa Maria; F1=São Paulo do Potengi; G1=Lagoa de Velhos; H1=Ruy Barbosa; I1=Bento Fernandes; J1=Av. Solange Nunes do Nascimento, 503 - Cidade Nova Natal e K1=Rua Érico Veríssimo, 3437 - Candelária, Natal. Conforme é apresentado na Tabela 6. 
Tabela 6: - Matriz relação de distância estimada entre todos os pontos da Rota 1.

\begin{tabular}{|c|c|c|c|c|c|c|c|c|c|c|c|}
\hline $\mathbf{5 4 5 , 3}$ & A1 & B1 & C1 & D1 & E1 & F1 & G1 & H1 & I1 & J1 & K1 \\
\hline A1 & 0 & 57,3 & 84,2 & 98,9 & 114 & 117 & 138 & 153 & 102 & 167 & 172 \\
\hline B1 & 57,3 & 0 & 36,6 & 60,2 & 75,5 & 78,8 & 99,3 & 115 & 63,1 & 129 & 134 \\
\hline C1 & 84,2 & 36,6 & 0 & 23,6 & 38,8 & 42,1 & 62,7 & 77,9 & 26,5 & 92,1 & 97,2 \\
\hline D1 & 98,9 & 60,2 & 23,6 & 0 & 15,8 & 19,1 & 39,7 & 54,9 & 16,3 & 69,2 & 74,2 \\
\hline E1 & 114 & 75,5 & 38,8 & 15,8 & 0 & 20,9 & 41,4 & 56,7 & 31,4 & 54,2 & 59,2 \\
\hline F1 & 117 & 78,8 & 42,1 & 19,1 & 20,9 & 0 & 22 & 37,3 & 34,8 & 74,2 & 79,2 \\
\hline G1 & 138 & 99,3 & 62,7 & 39,7 & 41,4 & 22 & 0 & 37,5 & 55,3 & 94,7 & 99,8 \\
\hline H1 & 153 & 115 & 77,9 & 54,9 & 56,7 & 37,3 & 37,5 & 0 & 70,6 & 110 & 115 \\
\hline 11 & 102 & 63,1 & 26,5 & 16,3 & 31,4 & 34,8 & 55,3 & 70,6 & 0 & 84,8 & 89,8 \\
\hline J1 & 167 & 129 & 92,1 & 69,2 & 54,2 & 74,2 & 94,7 & 110 & 84,8 & 0 & 4,2 \\
\hline K1 & 172 & 134 & 97,2 & 74,2 & 59,2 & 79,2 & 99,8 & 115 & 89,8 & 4,2 & 0 \\
\hline
\end{tabular}

Fonte: Elaborada pelos autores.

Em seguida, a matriz de solução contemplando as devidas restrições foi elaborada e estas foram adicionadas nos parâmetros do Solver. Destaca-se que devido à grande quantidade de variáveis analisadas, o número de iterações teve que ser ampliado para 1.000, bem como o tempo máximo para 1.000 segundos.

Tabela 7: Matriz resolução da Rota 1.

\begin{tabular}{|c|c|c|c|c|c|c|c|c|c|c|c|c|}
\hline 502,4 & $\mathbf{A 1}$ & B1 & $\mathrm{C1}$ & D1 & E1 & F1 & G1 & H1 & I1 & J1 & K1 & \\
\hline A1 & 0 & 1 & 0 & 0 & 0 & 0 & 0 & 0 & 0 & 0 & 0 & 1 \\
\hline B1 & 0 & 0 & 1 & 0 & 0 & 0 & 0 & 0 & 0 & 0 & 0 & 1 \\
\hline $\mathrm{C} 1$ & 0 & 0 & 0 & 0 & 0 & 0 & 0 & 0 & 1 & 0 & 0 & 1 \\
\hline D1 & 0 & 0 & 0 & 0 & 0 & 1 & 0 & 0 & 0 & 0 & 0 & 1 \\
\hline E1 & 0 & 0 & 0 & 0 & 0 & 0 & 0 & 0 & 0 & 1 & 0 & 1 \\
\hline F1 & 0 & 0 & 0 & 0 & 0 & 0 & 1 & 0 & 0 & 0 & 0 & 1 \\
\hline G1 & 0 & 0 & 0 & 0 & 0 & 0 & 0 & 1 & 0 & 0 & 0 & 1 \\
\hline H1 & 0 & 0 & 0 & 0 & 1 & 0 & 0 & 0 & 0 & 0 & 0 & 1 \\
\hline I1 & 0 & 0 & 0 & 1 & 0 & 0 & 0 & 0 & 0 & 0 & 0 & 1 \\
\hline $\mathbf{J 1}$ & 0 & 0 & 0 & 0 & 0 & 0 & 0 & 0 & 0 & 0 & 1 & 1 \\
\hline \multirow[t]{2}{*}{ K1 } & 1 & 0 & 0 & 0 & 0 & 0 & 0 & 0 & 0 & 0 & 0 & 1 \\
\hline & 1 & 1 & 1 & 1 & 1 & 1 & 1 & 1 & 1 & 1 & 1 & \\
\hline
\end{tabular}

Neste sentido, é possível identificar que o trajeto que minimizaria o total de quilômetros percorridos na Rota 1 é: $\mathrm{A} 1 » \mathrm{~B} 1 » \mathrm{C} 1 » \mathrm{I} 1 » \mathrm{D} 1 » \mathrm{~F} 1 » \mathrm{G} 1 » \mathrm{H} 1 » \mathrm{E} 1 » \mathrm{~J} 1 » \mathrm{~K} 1 » \mathrm{~A} 1$. A partir da função objetivo exibida na primeira linha e primeira coluna da matriz pode-se identificar que o estimado total percorrido pelo veículo neste itinerário será de aproximadamente $502,5 \mathrm{~km}$. Logo, constata-se que a partir da otimização no Solver, uma redução significativa de aproximadamente $42,9 \mathrm{~km}$ pôde ser identificada em relação ao itinerário definido pela heurística. Os pontos de distribuição referentes à Rota 2 foram identificados na matriz de relação de distância estimada da seguinte forma: A2; B2; C21. A matriz é apresentada na Tabela 8. Considerando que apenas 3 pontos foram analisados nesta rota, para a otimização deste problema não foi necessário 
inserir restrições de subciclos. Desta forma, o Solver apresentou a otimização na sua primeira execução. A matriz solução é apresentada na Tabela 9.

Tabela 8: Relação de distância estimada entre todos os pontos da Rota 2.

\begin{tabular}{|c|c|c|c|}
\hline $\mathbf{3 6 8 , 2}$ & $\mathbf{A 2}$ & $\mathbf{B 2}$ & $\mathbf{C 2}$ \\
\hline $\mathbf{A 2}$ & 0 & 117 & 172 \\
\hline $\mathbf{B 2}$ & 117 & 0 & 79,2 \\
\hline $\mathbf{C 2}$ & 172 & 79,2 & 0 \\
\hline
\end{tabular}

Fonte: Elaborada pelos autores.

Tabela 9: Matriz resolução da Rota 2.

\begin{tabular}{|c|c|c|c|}
\hline 368,2 & A2 & B2 & $\mathrm{C2}$ \\
\hline A2 & 0 & 1 & $\mathbf{0}$ \\
\hline B2 & 0 & 0 & 1 \\
\hline $\mathrm{C} 2$ & 1 & $\mathbf{0}$ & 0 \\
\hline
\end{tabular}

Fonte: Elaborada pelos autores.

De acordo com a solução gerada no Solver, a Rota 2 deverá ser executada da seguinte forma: $\mathrm{A} 2$ » $\mathrm{B} 2$ » $\mathrm{C} 2 » \mathrm{~A} 2$. Neste sentido, nenhuma alteração nesta rota deverá ser feita e o total mínimo percorrido pelo veículo é igual a aproximadamente $368,2 \mathrm{~km}$. Na Rota 3,11 pontos de distribuição são analisados. Estes pontos foram identificados na matriz relação de distância estimada do seguinte modo: A3; B3; C3; D3; E3; F3; G3; H3; I3; J3 e; K3. Conforme apresentado na Tabela 10.

Tabela 10: Matriz relação de distância estimada entre todos os pontos da Rota 3.

\begin{tabular}{|c|c|c|c|c|c|c|c|c|c|c|c|}
\hline $\mathbf{3 7 8 , 3}$ & $\mathbf{A 3}$ & $\mathbf{B 3}$ & $\mathbf{C 3}$ & $\mathbf{D 3}$ & $\mathbf{E 3}$ & $\mathbf{F 3}$ & $\mathbf{G 3}$ & $\mathbf{H 3}$ & $\mathbf{I 3}$ & $\mathbf{J 3}$ & $\mathbf{K 3}$ \\
\hline $\mathbf{A 3}$ & 0 & 172 & 175 & 176 & 171 & 173 & 170 & 180 & 179 & 179 & 174 \\
\hline $\mathbf{B 3}$ & 172 & 0 & 1,3 & 4,1 & 5,3 & 5,6 & 6,7 & 7,8 & 7,4 & 8 & 12,8 \\
\hline $\mathbf{C 3}$ & 175 & 1,3 & 0 & 2,5 & 4 & 4,6 & 5,8 & 6,2 & 5,9 & 6,2 & 11,4 \\
\hline $\mathbf{D 3}$ & 176 & 4,1 & 2,5 & 0 & 5,1 & 5,3 & 6,1 & 6,7 & 5,4 & 5,9 & 11,9 \\
\hline $\mathbf{E 3}$ & 171 & 5,3 & 4 & 5,1 & 0 & 1,4 & 1,6 & 4,5 & 4,8 & 5,1 & 8,2 \\
\hline $\mathbf{F 3}$ & 173 & 5,6 & 4,6 & 5,3 & 1,4 & 0 & 2,6 & 3,8 & 4,8 & 5,2 & 9,2 \\
\hline $\mathbf{G 3}$ & 170 & 6,7 & 5,8 & 6,1 & 1,6 & 2,6 & 0 & 5,1 & 6,2 & 6,5 & 6,6 \\
\hline $\mathbf{H 3}$ & 180 & 7,8 & 6,2 & 6,7 & 4,5 & 3,8 & 5,1 & 0 & 1,1 & 2,1 & 10 \\
\hline $\mathbf{I 3}$ & 179 & 7,4 & 5,9 & 5,4 & 4,8 & 4,8 & 6,2 & 1,1 & 0 & 1,8 & 10,6 \\
\hline $\mathbf{J 3}$ & 179 & 8 & 6,2 & 5,9 & 5,1 & 5,2 & 6,5 & 2,1 & 1,8 & 0 & 11,4 \\
\hline $\mathbf{K 3}$ & 174 & 12,8 & 11,4 & 11,9 & 8,2 & 9,2 & 6,6 & 10 & 10,6 & 11,4 & 0 \\
\hline
\end{tabular}

Fonte: Elaborada pelos autores.

Devido ao grande número de variáveis analisadas, vale ressaltar que as opções "Iterações" e "Tempo máximo" nos parâmetros do Solver tiveram que ser ampliadas para 1.000. Desta forma, a solução ótima pôde ser encontrada, conforme exibido na Tabela 11. 
Tabela 11: Matriz resolução da Rota 3.

\begin{tabular}{|c|c|c|c|c|c|c|c|c|c|c|c|}
\hline 372 & A3 & B3 & C3 & D3 & E3 & F3 & G3 & H3 & I3 & J3 & K3 \\
\hline A3 & 0 & 1 & 0 & 0 & 0 & 0 & 0 & 0 & 0 & 0 & 0 \\
\hline B3 & 0 & 0 & 1 & 0 & 0 & 0 & 0 & 0 & 0 & 0 & 0 \\
\hline C3 & 0 & 0 & 0 & 1 & 0 & 0 & 0 & 0 & 0 & 0 & 0 \\
\hline D3 & 0 & 0 & 0 & 0 & 0 & 0 & 0 & 0 & 0 & 1 & 0 \\
\hline E3 & 0 & 0 & 0 & 0 & 0 & 0 & 1 & 0 & 0 & 0 & 0 \\
\hline F3 & 0 & 0 & 0 & 0 & 1 & 0 & 0 & 0 & 0 & 0 & 0 \\
\hline G3 & 0 & 0 & 0 & 0 & 0 & 0 & 0 & 0 & 0 & 0 & 1 \\
\hline H3 & 0 & 0 & 0 & 0 & 0 & 1 & 0 & 0 & 0 & 0 & 0 \\
\hline I3 & 0 & 0 & 0 & 0 & 0 & 0 & 0 & 1 & 0 & 0 & 0 \\
\hline $\mathbf{J 3}$ & 0 & 0 & 0 & 0 & 0 & 0 & 0 & 0 & 1 & 0 & 0 \\
\hline \multirow[t]{2}{*}{ K3 } & 1 & 0 & 0 & 0 & 0 & 0 & 0 & 0 & 0 & 0 & 0 \\
\hline & 1 & 1 & 1 & 1 & 1 & 1 & 1 & 1 & 1 & 1 & 1 \\
\hline
\end{tabular}

Fonte: Elaborada pelos autores.

De acordo com a solução gerada pelo Solver, mudanças tiveram que ser realizadas na Rota 3, $\log$ o o itinerário deve ser executado da seguinte forma: $\mathrm{A} 3$ » $\mathrm{B} 3$ » $\mathrm{C} 3$ » $\mathrm{D} 3$ » $\mathrm{J} 3$ » $\mathrm{I} 3$ » $\mathrm{H} 3$ » $\mathrm{F} 3$ » $\mathrm{E} 3 » \mathrm{G} 3$ » $\mathrm{K} 3$ » $\mathrm{A} 3$. Neste sentido, foi possível identificar que, a partir da otimização da Rota 3 , que a distância estimada total percorrida pelo veículo é de aproximadamente $372 \mathrm{~km}$. Assim, uma redução aproximadamente de $6,3 \mathrm{~km}$ é considerada em relação à rota definida pela heurística.

$\mathrm{Na}$ Rota 4 apenas 4 pontos devem ser visitados. Estes são identificados na matriz de relação de distância da seguinte forma: A4= Angicos; B4=Pedra Preta; C4=Rua Macaé, 1994 - Potengi, Natal e D4= Av. Boa Sorte, 1834 - Nossa Sra. da Apresentação, Natal. A Tabela 12 exibe a matriz relação de distâncias entre os 4 pontos.

Tabela 12: Matriz relação de distância estimada entre todos os pontos da Rota 4.

\begin{tabular}{|c|c|c|c|c|}
\hline $\mathbf{4 2 8 , 1}$ & A4 & B4 & C4 & D4 \\
\hline A4 & 0 & 84,2 & 174 & 178 \\
\hline B4 & 84,2 & 0 & 162 & 166 \\
\hline C4 & 174 & 162 & 0 & 3,9 \\
\hline D4 & 178 & 166 & 3,9 & 0 \\
\hline
\end{tabular}

Fonte: Elaborada pelos autores.

Devido ao pequeno número de variáveis analisadas, a otimização do problema pode rapidamente ser identificada, fazendo-se necessária a inserção de apenas uma restrição de subciclo. A Tabela 13 apresenta a solução gerada pelo Solver.

Tabela 13: Matriz resolução da Rota 4.

\begin{tabular}{|c|c|c|c|c|c|}
\hline 428,1 & A4 & B4 & $\mathrm{C} 4$ & D4 & \\
\hline A4 & 0 & 1 & 0 & 0 & 1 \\
\hline B4 & 0 & 0 & 0 & 1 & 1 \\
\hline $\mathrm{C} 4$ & 1 & 0 & 0 & 0 & 1 \\
\hline \multirow[t]{2}{*}{ D4 } & 0 & 0 & 1 & 0 & 1 \\
\hline & 1 & 1 & 1 & 1 & \\
\hline
\end{tabular}


De acordo com a resolução gerada, o itinerário deve ser seguido deste modo: A4 » B4 » D4 » $\mathrm{C} 4$ » A4. Nota-se que os pontos C4 e D4 foram invertidos, porém a distância estimada total percorrida permaneceu igual a aproximadamente $428,1 \mathrm{~km}$. Logo, os dois itinerários resultam na distância estimada mínima em que o veículo poderia trafegar nesta rota.

Tendo em vista que as novas rotas foram definidas e otimizadas, faz-se necessário designálas a cada dia da semana. Uma restrição do problema impõe que o atendimento da cidade São Paulo do Potengi seja feito duas vezes na semana e que estes tenham um intervalo de no mínimo 1 dia. Logo, as Rotas 1 e 2 não podem ser designadas em dias consecutivos.

Visando balancear a distribuição dos produtos comerciais aos centros de distribuição e sabendo que a Rota 2 e Rota 4 transportam as maiores quantidades de produtos comerciais aos centros de distribuição, é adequado designá-las com um intervalo de 4 dias. Além disso, tendo em vista que a cidade São Paulo do Potengi é atendida pela Rota 1 e Rota 2, estas devem ser designadas com um intervalo mínimo de 1 dia.

Desta forma, as rotas diárias foram designadas do seguinte modo: Rota 1 realizada no sábado; Rota 2 na segunda-feira; Rota 3 na quarta-feira e a Rota 4 na sexta-feira. Neste sentido, um total de 15.000 litros será distribuído às segundas-feiras, deste total, 1.725 litros correspondem ao leite institucional, 11.675 litros ao leite comercial e 1.600 litros correspondem às bebidas lácteas. Nas quartas-feiras, 8.250 litros de leite institucional, 6.050 litros de leite comercial e 700 litros de bebidas lácteas são entregues, totalizando uma distribuição de 15.000 litros de produtos. Nas sextas-feiras, 13.985 litros de produtos são distribuídos ao total, logo, 2.355 litros correspondem ao leite institucional, 10.030 litros ao leite comercial e 1.600 litros as bebidas lácteas. Por fim, o total distribuído aos sábados serão 15.000 litros de produtos, dentre estes: 11.955 litros correspondem ao leite institucional, 2.345 ao leite comercial e 700 litros correspondem às bebidas lácteas. A Tabela 14 expõe a designação das rotas aos dias da semana.

Tabela 14: Designação das rotas aos dias da semana.

\begin{tabular}{|c|c|c|}
\hline Dias na semana & Rotas designadas & Volume de distribuição (litros) \\
\hline Segunda-feira & Rota 2 & 15000 \\
\hline Terça-feira & - & - \\
\hline Quarta-feira & Rota 3 & 15000 \\
\hline Quinta-feira & - & - \\
\hline Sexta-feira & Rota 4 & 13985 \\
\hline Sábado & Rota 1 & 15000 \\
\hline
\end{tabular}

Fonte: Elaborada pelos autores.

\subsection{Discussões}

Tendo as rotas designadas aos respectivos dias, realizou-se uma análise comparativa entre o plano atual de distribuição e o plano proposto. Atualmente, o veículo desloca-se 6 dias na semana para que a demanda seja atendida, em contrapartida, o cenário proposto sugere que $\mathrm{o}$ veículo se desloque apenas 4 dias na semana. A Tabela 15 exibe o plano atual de distribuição.

De acordo com o plano de distribuição atual, a demanda total semanal é de 24.285 litros de leite institucional, 30.100 litros de leite comercial e 4.600 litros de bebidas lácteas. Neste sentido, o plano de distribuição proposto deve atender a toda demanda semanal igualmente. A Tabela 16 apresenta o plano de distribuição proposto. 
Tabela 15: Plano de distribuição atual.

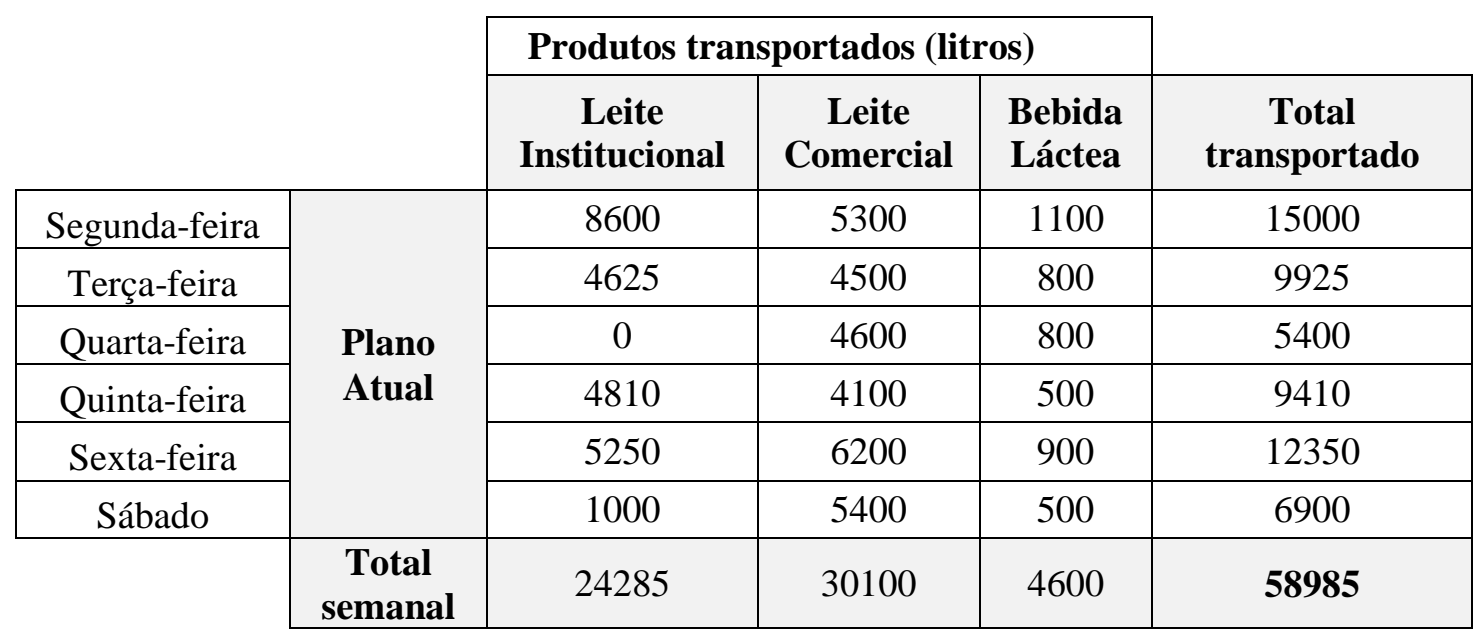

Fonte: Elaborada pelos autores.

Tabela 16: Plano de distribuição proposto.

\begin{tabular}{|c|c|c|c|c|c|}
\hline & \multirow{2}{*}{\multicolumn{3}{|c|}{ Produtos transportados (litros) }} & \multirow[b]{3}{*}{$\begin{array}{c}\text { Total } \\
\text { transportado } \\
\text { (litros) }\end{array}$} \\
\hline & & & & & \\
\hline & & $\begin{array}{c}\text { Leite } \\
\text { Institucional }\end{array}$ & $\begin{array}{c}\text { Leite } \\
\text { Comercial }\end{array}$ & $\begin{array}{l}\text { Bebida } \\
\text { Láctea }\end{array}$ & \\
\hline Segunda-feira & \multirow{6}{*}{$\begin{array}{c}\text { Plano } \\
\text { Proposto }\end{array}$} & 1725 & 11675 & 1600 & 15000 \\
\hline Terça-feira & & - & - & - & - \\
\hline Quarta-feira & & 8250 & 6050 & 700 & 15000 \\
\hline Quinta-feira & & - & - & - & - \\
\hline Sexta-feira & & 2355 & 10030 & 1600 & 13985 \\
\hline \multirow[t]{2}{*}{ Sábado } & & 11955 & 2345 & 700 & 15000 \\
\hline & $\begin{array}{c}\text { Total } \\
\text { semanal }\end{array}$ & 24285 & 30100 & 4600 & 58985 \\
\hline
\end{tabular}

Fonte: Elaborada pelos autores.

Tendo o plano de distribuição proposto definido, a análise comparativa, considerando a utilização de capacidade e total de quilômetros percorridos diariamente, entre os dois cenários é exibida na Tabela 17.

De acordo com a análise comparativa, podem ser identificadas vantagens significativas com a implantação de um novo plano de rotas.

Inicialmente, a baixa utilização da capacidade do veículo impacta negativamente o plano de rotas atual, já que este desloca-se 6 dias da semana para atender sua demanda semanal, enquanto a proposta resulta na redução do deslocamento do veículo para 4 dias na semana.

Tendo em vista que o veículo Mercedes-Benz MB 1620 tem um consumo médio de aproximadamente $3,5 \mathrm{Km}$ por litro de combustível, o preço médio, considerando os valores do diesel atuais nos postos de combustível onde o veículo comumente abastece, foi obtido: Posto 1= $\mathrm{R} \$ 3,09$; Posto 2= R \$ 3,10; Posto 3=R \$ 3,09 e Posto 4= R\$ 3,11. Desta forma, o custo médio por litro de combustível é aproximadamente $\mathrm{R} \$ 3,10$.

Logo, em termos monetários, o impacto do plano de rotas proposto traria uma economia estimada de R \$777,92 por semana, correspondendo a um fechamento mensal de aproximadamente $\mathrm{R} \$ 3.111,70$. Como os custos de transporte (consumo de combustível por quilometro percorrido) atuais são estimados em 2.257,68 reais por semana, esta economia representa uma diminuição de aproximadamente $34,46 \%$ dos custos de transporte com o plano atual. Neste contexto, sabendo que a empresa estudada é de pequeno porte, observa-se que os 
resultados financeiros impactariam significativamente o aumento dos seus lucros em uma perspectiva anual, conforme apresentado na Figura 3.

Tabela 17: Análise comparativa entre o plano de distribuição atual e proposto.

\begin{tabular}{|c|c|c|c|c|}
\cline { 2 - 5 } \multicolumn{1}{c|}{} & \multicolumn{2}{c|}{ PLANO ATUAL } & \multicolumn{2}{c|}{ PLANO PROPOSTO } \\
\cline { 2 - 5 } & $\begin{array}{c}\text { Total percorrido } \\
(\mathbf{k m})\end{array}$ & $\begin{array}{c}\text { Utilização da } \\
\text { capacidade (\%) }\end{array}$ & $\begin{array}{c}\text { Total percorrido } \\
\mathbf{( k m )}\end{array}$ & $\begin{array}{c}\text { Utilização da } \\
\text { capacidade (\%) }\end{array}$ \\
\hline Segunda-feira & 561 & 100,00 & 368,2 & 100,00 \\
\hline Terça-feira & 399 & 66,17 & - & - \\
\hline Quarta-feira & 360 & 36,00 & 372 & 100,00 \\
\hline Quinta-feira & 483 & 62,73 & - & - \\
\hline Sexta-feira & 384 & 82,33 & 428,1 & 93,23 \\
\hline Sábado & 362 & 46,00 & 502,4 & 100,00 \\
\hline Total Semanal & $\mathbf{2 5 4 9 , 0}$ & & $\mathbf{1 6 7 0 , 7}$ & \\
\hline
\end{tabular}

Fonte: Elaborada pelos autores.

Figura 3: Representação anual da estimativa financeira entre plano atual e proposto.

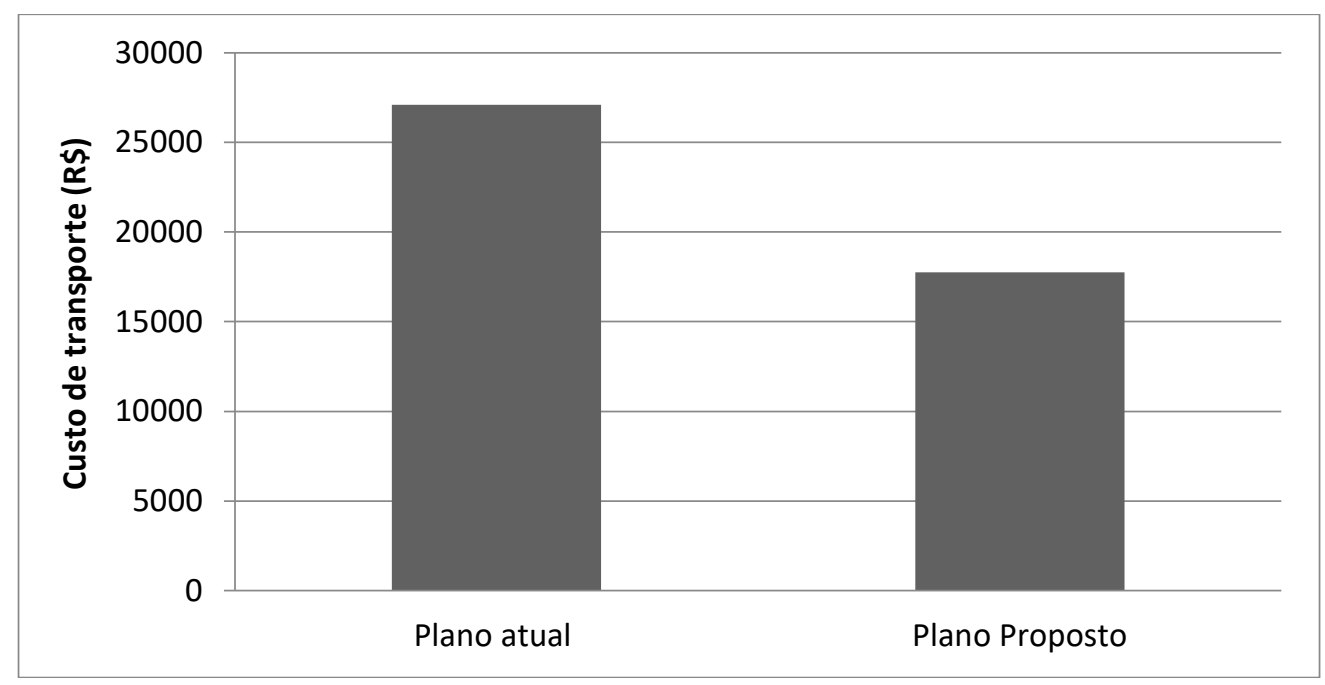

Fonte: Elaborada pelos autores.

O plano de roteirização proposto atende às restrições da empresa e traz impactos expressivos no tocante a redução de custos de transporte e eficiência da utilização da capacidade do seu recurso. Sua implementação é viável e significativa, pois, além da redução dos custos de transporte, contribui para sua perspectiva de crescimento e corrobora com o desenvolvimento econômico da região em que esta inserida.

\section{Conclusões}

A distribuição física de produtos é apoiada pelo plano estruturado de roteirização. A partir dele, os veículos podem ser otimizados e os roteiros planejados, de forma que a eficiência logística seja atendida através da devida utilização dos recursos disponíveis, redução de quilômetros percorridos e consequentemente a diminuição dos custos.

Diante das informações obtidas sobre o plano atual de distribuição, pode-se constatar que a empresa não dispunha de um plano estruturado de rotas. O plano atual, além de se ter sido constituído de forma empírica, adéqua-se a uma demanda de leite institucional recentemente modificada, logo, a atual configuração da demanda do leite institucional não vem sendo 
considerada pela empresa para que um plano mais eficiente seja realizado. Nesta ocorrência, a utilização da capacidade não é aproveitada de forma eficiente e o veículo é designado desnecessariamente em 6 dias na semana para atender a demanda semanal. Desta forma, o veículo percorre aproximadamente 2.549 quilômetros por semana, acarretando em um custo semanal de aproximadamente $\mathrm{R} \$ 2.257,68$ com combustível.

Para que as novas rotas diárias fossem definidas, na fase de elaboração do plano de rotas proposto adotou-se a heurística do VMP para que os vizinhos mais próximos, a partir do ponto de origem, pudessem ser identificados, a aplicação desta heurística consiste na sua fácil aplicação e adequação ao problema estudado, fornecendo resultados viáveis para o estudo de caso, porém, outros métodos heurísticos mais sofisticados poderiam ter sido utilizados para esta finalidade. Com a aplicação da heurística, a proximidade entre todos os pontos foi conhecida e, a partir de então, os pontos mais próximos foram agrupados em rotas diárias, de modo que a restrição de capacidade do veículo fosse atendida.

A designação das rotas a cada dia da semana considerou a restrição da cidade São Paulo do Potengi, que deve ter sua demanda atendida duas vezes na semana em um intervalo mínimo de 1 dia. Durante a análise dos resultados do VMP, observou-se que a Rota 2 e Rota 4 transportam as maiores quantidades de produtos comerciais aos centros de distribuição. Desta forma, é interessante designá-las com um intervalo de 4 dias.

Neste sentido, a utilização da capacidade na segunda-feira, quarta-feira e sábado é de $100 \%$, enquanto na sexta-feira 93,23\% da capacidade é aproveitada. Assim, toda a demanda semanal pode ser atendida com as 4 rotas. Ademais, os resultados obtidos com a heurística foram aprimorados com a implementação do Modelo de Dantzig na otimização de cada uma das rotas, resultando em uma redução de 49,2 quilômetros por semana.

Tendo o plano de distribuição proposto definido, foi possível observar que, se o novo plano de rotas for implantado, o veículo passará a percorrer um total de 1670,7 quilômetros por semana. Desta forma o custo de transporte será reduzido para $\mathrm{R} \$ 1.479,76$. A partir da diminuição do total de quilômetros percorridos na semana, ocorrerá uma economia de $\mathrm{R} \$ 2722,73$ do plano proposto frente ao atual. Em uma análise anual, a rota proposta implantada corresponde a um significativo ganho de aproximadamente $\mathrm{R} \$ 37.304,40$. Sabendo que a empresa estudada é classificada a partir de seu número de funcionários como de pequeno porte, um impacto financeiro desta amplitude traria diversos benefícios para a organização.

Além disso, tendo em vista que o veículo Mercedes-Benz MB 1620 é o veículo que dispõe da maior capacidade dentre todos os veículos da frota. Vale ressaltar que a partir da redução de dias no planejamento de rotas, a disponibilidade deste recurso aumenta. Logo, o veículo poderá ser alocado à outra rota ou atividade. O motorista e seu ajudante também terão uma maior disponibilidade para a designação em outras atribuições.

Apesar do pequeno porte, a empresa estudada é extremamente importante para o cenário econômico da comunidade local. Ela fomenta as atividades de ovinocaprinocultura, subsidia produtores rurais locais assistindo mais de 31 produtores da região, gerando empregos diretos e indiretos bem como fornece seus produtos para atender a demanda de toda região em que está inserida. Vale ressaltar que os clássicos métodos utilizados, se devidamente adequados ao problema em um contexto simplificado, podem influenciar de forma significativa aos resultados obtidos com a elaboração de plano de roteirização racional. Isto é, impactando na redução de custos e eficiência da utilização dos recursos.

Como sugestões de trabalhos futuros, pretende-se a análise comparativa entre novos conjuntos de soluções factíveis gerados a partir da utilização de meta-heurísticas e métodos heurísticos, tais como: Simulated Annealing, GRASP, K-OPT entre outros. Também sugere-se utilização de outros softwares de otimização, tais como: RoadNet, TransCad, Route Pro, TruckStops, RoadShow,Territory, Planner. 


\section{Referências}

Ahmed, Belal., Chouhan, S. S., Biswas, S., Gayathri, P. e Santhi, H. Analysis of travelling salesman problem. IOP Conference Series: Materials Science and Engineering, v. 263, n. 4, p.042085, 2017.

Ancau, M. The performances of a general optimization algorithm in solving travelling salesman problem. Annals of DAAAM \& Proceedings, p. 5+, 2005

Bang-Jensen, J. e Hell, P. The effect of two cycles on the complexity of colourings by directed graphs. Discrete Applied Mathematics, v. 26, n. 1, p. 1-23, 1990.

Bellmore, M. e Nemhauser, G. L. The traveling salesman problem: A survey. Operations Research, v. 16, n. 3, p. 538-558, 1968.

Cacchiani, V., Hemmelmayr, V. C. e Tricoire, F. A set-covering based heuristic algorithm for the periodic vehicle routing problem. Discrete Applied Mathematics, v. 163, p. 53-64, 2014.

Calado, F. M. e Ladeira, A. P. Problema do caixeiro viajante: Um estudo comparativo de técnicas de inteligência artificial. Exacta, v. 4, n. 1, p. 5-16, 2011.

Caria, M., Todde, G. e Pazzona, A. Modelling the collection and delivery of sheep milk: A tool to optimise the logistics costs of cheese factories. Agriculture, v. 8, n. 1, p. 5-21, 2018.

Chung, C. A. Simulation Modeling Handbook: a practical approach. Florida: CRC Press, 2004. Ewbank, H., Wanke, P. e Hadi-Vencheh, A. An unsupervised fuzzy clustering approach to the capacitated vehicle routing problem. Neural Computing and Applications, v. 27, n. 4, p. 857-867, 2016.

Fonseca, J. J. S. Metodologia da Pesquisa Científica, Fortaleza: Editora da UECE, 2002. Apostila. Franco Júnior, E. F. e Oliveira, H. C. B. Adaptação da meta-heurística GRASP na resolução do problema de roteamento de veículos com janela de tempo. Revista Eletrônica Pesquisa Operacional para o Desenvolvimento, v. 4, n. 3, p. 271-287, 2012.

Gerhardt, T. E. e Silveira, D. T. (orgs.). Métodos de Pesquisa. $1^{\text {a }}$ ed. Porto Alegre: Editora da UFRGS, 2009.

Gil, A. C. Como Elaborar Projetos de Pesquisa. $4^{\mathrm{a}}$ ed. São Paulo: Atlas, 2007.

Goldbarg, M. C. e Luna, H. P. L. Otimização Combinatória e Programação Linear. $2^{\mathrm{a}}$ ed. Rio de Janeiro: Elsevier, 2005.

Johnson, D. S. Approximation algorithms for combinatorial problems. Journal of Computer and System Sciences, v. 9, n. 3, p. 256-278, 1974.

Laporte, G. The vehicle routing problem: an overview of exact and approximate algorithms. European Journal of Operational Research, v. 59, n. 3, p. 345-358, 1992. 
Layeb, A., Ammi, M. e Chikhi, S. A GRASP algorithm based on new randomized heuristic for vehicle routing problem. Journal of Computing and Information Technology, v. 21, n. 1, p. 3546, 2013.

Leite, L. O. e Júnior, A. C. G. Problema de roteamento de veículos com coleta e entrega simultânea: um estudo de caso em uma indústria de alimentos localizada na região do Vale do Aço. Revista Latino-Americana de Inovação e Engenharia de Produção, v. 5, n. 7, p. 101-115, 2017.

Martins, L. F. F. e Lopes, L. A. S. Roteirização de veículos de cargas perecíveis usando sistema de informações geográficas. Revista Militar de Ciência e Tecnologia, v. 31, n. 3, p. 51-66, 2014.

Matai, R., Singh, S. P. e Mittal, M. L. Traveling salesman problem: An overview of applications, formulations, and solution approaches. In: Davendra, D. (ed.) Traveling Salesman Problem, Theory and Applications. Rijeka, Croácia: InTech, 2010. p. 1-25.

Pereira, I. C. Proposta de sistematização da simulação para fabricação em lotes. Dissertação (Mestrado em Engenharia de Produção) - Programa de Pós-Graduação em Engenharia de Produção, Universidade Federal de Itajubá, Itajubá-MG, 2000.

Peres, C. e Nunes, F. C. O que os dados do IBGE dizem sobre o leite. Revista mais Leite, $\mathrm{n}^{\circ} 06$. São Paulo: Editora Rocha, 2011.

Ribeiro, P. C. C., Andrade, A. M. e Silva, F. A. Evaluation of Transportation Management System in logistic operations in a beverage company. Revista Gestão da Produção Operações e Sistemas, v. 13, n. 2, p. 1-20, 2018.

Salas, Y. J. C., Ledón, R. A., Osés, C. M. e Machad, N. C. Asistencia decisional en el proceso de optimización para el enrutamiento de vehículos. Ingeniería Industrial, v. 31, n. 1, p. 1-7, 2010.

Seixas, M. P. Heuristic and exact methods applied to a rich vehicle routing and scheduling problem. Tese (Doutorado em Engenharia Naval e Oceânica) - Escola Politécnica, Universidade de São Paulo, São Paulo-SP, 2013.

Silva, D. F. e Sanches, A. L. Aplicação conjunta do método de Dijkstra e otimização combinatória para solução do problema do caixeiro viajante. Anais do XIV Simpósio de Excelência em Gestão e Tecnologia SEGET, Resende, RJ, 2009.

Song, B. D. e Ko, Y. D. A vehicle routing problem of both refrigerated- and general-type vehicles for perishable food products delivery. Journal of Food Engineering, v. 169, p. 61-71, 2016.

Souza, A. W., Amaral, D. B. M., Oi, R. K., Carneiro, J. B. e Fontebasso Neto, J. Aplicação do método de varredura na roteirização de frota em uma empresa de transporte e distribuição de cargas fracionadas. Exacta, v. 14, n. 1, p. 1-10, 2016.

Souza Neto, J. F. Modelagem e meta-heurísticas para o problema de roteamento de veículos com janelas de tempo, múltiplos entregadores e múltiplas viagens em uma empresa de distribuição de 
bebidas. 119 f. Dissertação (Mestrado em Engenharia de Produção) - Departamento de Engenharia de Produção, Universidade Federal de São Carlos, São Carlos-SP, 2016.

Teixeira, L. L. Roteiro de Estudos de Pesquisa Operacional. Universidade Tecnológica Federal do Paraná, Medianeira, $2014 . \quad$ Disponível em: http://www.md.utfpr.edu.br/Intranet/professores/index.php?idusuario=158. Acesso em: 02/09/2018.

Tormen, A. F., Pansera, G. e Kripka, M. Otimização das rotas para veículos de manutenção do sistema de iluminação pública na cidade de Passo Fundo (RS). Exacta, v. 16, n. 3, p. 89-101, 2018. 